\title{
ESTEREOTIPOS DE GÉNERO Y ACTITUDES SEXISTAS DE LA POBLACIÓN ESCOLAR EXTREMEÑA
}

GENDER STEREOTYPES AND SEXIST ATTITUDES IN EXTREMADURA'S
SCHOOL POPULATION

Fernando González Pozuelo

Universidad de Extremadura. España/Spain fpozuelo@unex.es

Recibido/Received: 30/04/08

Aceptado/Accepted: 18/07/08

\section{RESUMEN}

El proceso de investigación aquí propuesto gira en torno a una realidad sociológica bien concreta: conocer hasta qué punto se han superado en las y los escolares extremeños de primaria y secundaria las creencias que justifican y conducen al sexismo y la violencia de género.

Nuestro propósito es proporcionar los datos y análisis indispensables que sirvan para poder desarrollar programas de intervención que permitan reducir las condiciones de riesgo detectadas para favorecer la construcción de la igualdad y la prevención de la violencia contra la mujer desde la Educación Primaria y Secundaria.

\section{PALABRAS CLAVE}

Sexismo, violencia de género, escolares extremeños.

\section{ABSTRACT}

This research process will study a specific sociological reality: to know to what extent the students of Primary and Secondary Education have overcome the beliefs that justify the sexism and the domestic violence.

Our purpose is to provide the information and indispensable analyses for the development of intervention programs for the reduction of the conditions of risk with the purpose of getting the construction of the equality and the prevention of the domestic violence from Primary and Secondary Education.

\section{KEYWORDS}

Sexism, domestic violence, Extremadura schoolboys and girls. 


\section{OBJETIVOS}

El objetivo general de este estudio es conocer hasta qué punto se han superado entre las y los escolares extremeños pertenecientes a los cursos terminales de la educación primaria y todos los de la secundaria obligatoria las creencias que justifican y conducen al sexismo.

\section{METODOLOGÍA EMPLEADA}

Respondiendo en el planteamiento e instrumentación a los objetivos propuestos y partiendo de la escasez de información preexistente sobre los/as escolares extremeños/as, se proyectó una amplia encuesta dirigida a todo el alumnado extremeño de $5^{\circ}$ de Primaria a $4^{\circ}$ de ESO.

En primer lugar, se procedió a hacer un inventario de temas sobre el objetivo de estudio. A partir del inventario de temas se llegó a elaborar un amplio dossier de baterías de preguntas, que hubiesen sido ya probadas en otros estudios.

La elaboración y revisión del cuestionario fue la parte más meticulosa y lenta de todo el proceso, ya que debíamos tener en todo momento muy clara la diversidad de objetivos a cubrir y la necesidad de recabar la máxima información posible de una manera clara y sintética; si tenemos en cuenta que la eficacia de una investigación sociológica depende en gran manera del cuestionario realizado, podremos comprender que su construcción fue muy laboriosa.

Una vez realizado el cuestionario, compuesto por 35 ítems que pretendían tomar el pulso al problema, se aplicó a una muestra significativa (cuestionario piloto), para ver los posibles errores y dificultades. Las modificaciones que se llevaron a cabo fueron más de tipo formal que de contenido.

\section{RECOGIDA DE DATOS}

La recogida de la información se realizó a través de un cuestionario precodificado de 35 ítems, algunos de ellos de respuesta múltiple. Para este artículo sólo utilizamos los que aparecen que son una pequeña parte del trabajo que estamos realizando.

Los cuestionarios fueron aplicados en su mayoría durante los meses de marzo, abril, mayo y junio de 2006 por una red de entrevistadores/as previamente instruidos y preparados para tal fin.

Las técnicas cuantitativas fueron completadas en el 2006 y 2007 por otras cualitativas. Dentro de la metodología cualitativa y de la técnica "grupos de discusión", se incluyeron técnicas complementarias, como son los ejercicios proyectivos, que suponen una fuente importante para la interpretación simbólica y 
que aportan un tipo de información más rica y matizada que la proporcionada por las técnicas cuantitativas.

\section{DISEÑO DE LA MUESTRA}

Se realizaron 2.641 encuestas y numerosos grupos de discusión en cuya composición y distribución se consideraron los siguientes criterios dentro del universo del alumnado estudiado:

- Tipo de centro (públicos y concertados)

- Zonas (urbana, semiurbana y rural)

- Sexo

- Edad y curso

- Creencias religiosas

\section{a) Tipo de centro}

Se consideró necesario tener en cuenta los dos tipos de centros escolares: públicos y concertados, dándose mayor peso a los centros públicos porque así se respetaba la representatividad de éstos en el conjunto de los centros escolares.

\section{b) Zonas}

Todas las zonas urbanas, semiurbanas y rurales, tanto de Cáceres como de Badajoz, están representadas en el estudio. Dentro de las zonas urbanas seleccionamos proporcionalmente colegios situados en el centro, la periferia y la semiperiferia.

El número de localidades visitadas para seleccionar las muestras rondó las setenta.

A nivel operativo atribuimos el término urbano a las ciudades de Cáceres y Badajoz, el de semiurbano a las poblaciones mayores de diez mil habitantes y el de rural a las localidades menores de diez mil habitantes.

\section{c) Sexo}

La variable sexo femenino o masculino en el alumnado, pareció significativa y relevante para afrontar el tema del estudio. Los dos sexos están proporcionalmente representados en todas las zonas.

\section{d) Edad y curso}

Las personas objeto del estudio son escolares de $5^{\circ}$ de Primaria a $4^{\circ}$ de ESO, con edades comprendidas entre los 10 y los 17 años.

El tamaño de la muestra fue de 2641 cuestionarios aplicados y recogidos lo que conlleva un margen de confianza nunca inferior al 95,5\% con un límite 
máximo de error de $+/-2 \%$ para los totales, según las tablas estadísticas de Arkin y Colton.

Todas las encuestas realizadas fueron supervisadas, eliminando aquellas que presentaban errores graves de comprensión o de falta de sinceridad.

En conjunto los trabajos de campo fueron muy laboriosos y fructíferos. La lectura de los datos puede corroborar en algunos puntos la calidad obtenida y una prueba inmediata es, por ejemplo, el bajo porcentaje de no respuestas tanto de hecho como de opinión y actitud.

\section{e) Creencias y prácticas religiosas}

Hemos considerado la posible incidencia de las creencias y prácticas religiosas en determinados comportamientos de nuestros escolares, de manera especial en el campo de los valores y respeto de sus compañeros

\section{ESTEREOTIPOS Y ACTITUDES SEXISTAS}

A menudo se nos olvida, que las diferencias entre hombres y mujeres no son diferencias innatas, y resulta difícil creer que los niños y las niñas no nacen con papeles sociales establecidos, sino que son educados de acuerdo con unos roles culturales que también, respecto al sexo, están en muchos casos estereotipados, reforzando, a veces sin querer y otras queriéndolo, atributos a un grupo o categoría social, que indudablemente facilitan mucho el funcionamiento y el "entendimiento" de las cosas, pero también mantienen el reparto desigual de los espacios y papeles en la vida, que sin duda necesita de análisis y revisión.

La asignación de estos atributos, en muchos casos negativos, pero no siempre, es uno de los mecanismos sobre los que hay que actuar, en el caso de la discriminación sexual aún vigente, que tiene como sabemos profundas raíces históricas en la estructura de nuestra actual sociedad, y por supuesto, en los mecanismos de reproducción social e ideológica.

Eliminar tal situación supone actuar sobre aquellos mecanismos que las generan y la perpetúan. Supone actuar sobre los niveles de las ideas, de las imágenes, de los estereotipos.

Definiendo el estereotipo como una imagen o idea aceptada comúnmente por un grupo o sociedad con carácter inmutable .Es importante distinguir entre:

- estereotipos de carácter individual, las creencias de una persona en su relación con un grupo o categoría social, y comunidad.

- estereotipos culturales, aquellas creencias compartidas por una

El análisis de la transmisión y asimilación de los mismos sigue siendo complejo y además muy diversificado. En el caso de los estereotipos relacionados 
con el sexo, sabemos que estos van asociados a conductas de rol, características físicas y otras que complican aún más su análisis.

Los estudios realizados sobre la transmisión verbal y actitudinal en las aulas, respecto a los mensajes y la forma de educar a los/as escolares indican que desde hace más de dos décadas, se ha superado la tradicional forma de diferenciación educativa entre niños y niñas. Es cierto que ya no se producen mensajes específicos de diferenciación sexual, y mucho menos de forma explícita.

Ya no se dan mensajes estereotipados del tipo:

"las niñas deben ser más limpias., deben sentarse de tal o cual forma... no deben correr..."

"los niños no deben llorar. Eso es cosa de niñas... no deben tener miedo... han de ser valientes..."

Estos mensajes explícitos han desaparecido de las aulas, o al menos sólo quedan en casos muy excepcionales. ¿Pero es igualmente cierto que el mensaje implícito no es diferenciador? ¿Es del todo cierto que no se dan reparto de papeles por género en las tareas y actividades escolares?

Los estudios realizados por el Instituto de la Mujer, sobre "Transmisión de los géneros en la escuela mixta", nos indican que pese a los avances educativos de igualdad, no existe verdadera coeducación en las aulas. Eliminar el sexismo en los procesos educativos, requiere instaurar igualdad de atención y acción sobre niños y niñas. Pero más difícil aún, exige rehacer el sistema de valores y actitudes que se transmiten. Exige la revisión de las atribuciones en función del sexo y la utilización de instrumentos y medidas para eliminar los rasgos sexistas que perviven. Pero si esto ocurre en las aulas, ¿Qué sucede fuera, en la calle y en casa?

Los niños y las niñas aprenden de sus padres, de sus profesores/as, de su entorno más cercano, de la televisión, de los libros, toman sus modelos y forman su concepto del mundo y de los demás, acoplando su comportamiento, en función de los modelos que les sirven, en muchos casos estereotipados, de los que se espera de ellos y de ellas.

En general, los niños, toman como modelo a sus padres y se forman una idea de las mujeres según el modelo de su madre. Las niñas, toman de modelo a su madre y se forman su concepto de los hombres según su padre. Pero hay otros muchos modelos como hemos dicho que amoldan y perfilan el propio.

La televisión, por ejemplo, con la publicidad absolutamente estereotipada, define modelos masculinos y femeninos tendiendo a perpetuar y mantener los valores sociales del hombre y de la mujer. Al asignar a las mujeres una realidad secundaria, inferior a la del hombre, definiendo rasgos como la ternura, la limpieza, el orden, la belleza, la dulzura, en definitiva rasgos propios del mundo de los afectos. En cambio define rasgos en los hombres como la creatividad, la osadía, el dominio, el triunfo, propios del mundo de los logros. 
La verdadera controversia de los estereotipos sexuales, sería conocer si tienen un fondo de verdad o no. Es decir si los atributos o rasgos de personalidad por el hecho de ser hombre o mujer, son absolutamente ciertos o no lo son.

Pero lo que nos parece más interesante, es la función que cumplen los estereotipos, más concretamente el hecho de estereotipar. Esta función, entre otras no menos interesantes, es la del control social. La que permite el mantenimiento de un status quo. La que el grupo dominante o de poder, ejerce al estereotipar, siempre por comparación.

Evidentemente, existen otros aspectos que favorecen el cambio positivo hacia la unificación de los rasgos de las personas, sin distinción del sexo, pero ya vimos que este tipo de estereotipos va muy ligado a la estructura social vigente, y al reparto y asignación de funciones y papeles en la sociedad.

Mientras los cambios dependan, en gran medida de la construcción de una realidad, no solo de las ideas, de por sí complejas, sino de la realidad más cotidiana y palpable de lo que enseñamos en las instituciones, ya sean primarias, como la familia, o secundarias como la escuela, los grupos, las organizaciones, los obstáculos por salvar son muchos todavía.

Para conocer la asimilación de los estereotipos sexuales de los escolares extremeños, se plantearon en la encuesta dos preguntas específicas.

Una concreta, descriptiva de los rasgos de personalidad de una persona, para identificarla en un género o no. Y otra, del grado de acuerdo o desacuerdo ante afirmaciones contundentes o sutiles pero aún frecuentes, que están más relacionadas con los roles y las características de los mismos en nuestra estructura social.

Se escapa de este estudio la forma de transmisión pero podemos deducir algunas hipótesis, unas ideas que nos sirvan para seguir profundizando.

El análisis de campo de qué grado y cómo los estereotipos dominantes respecto al género, están asimilados en nuestros escolares mediante su opinión al respecto, nos ofrecen unos datos muy interesantes, que analizamos a continuación.

El estudio de los resultados de las encuestas, en este apartado, los hemos realizado desde distintas variables:

- En primer lugar teniendo en cuenta la variable sexo en la respuesta, por lo que pudiera tener de significativo la asociación del estereotipo desde el grupo social diferenciador.

- En segundo lugar con la variable edad, con el objeto de saber si el factor edad constituye un elemento de mayor o menor implementación del estereotipo.

- Por último con la variable de zona de residencia, diferenciada en función de los criterios previamente establecidos: urbana, semiurbana y rural, el objetivo era el mismo, conocer si la implementación de los estereotipos sexuales, son más latentes en función de estructuras sociales más o menos tradicionales. Los resultados son los siguientes: 
Pregunta 1: A continuación te presentamos una lista de descripciones de personas, queremos que nos digas si piensas que la persona descrita es un hombre, una mujer o, si podría ser cualquiera de las dos:

Tabla 1. Respuestas de los niños

\begin{tabular}{lccc} 
& HOMBRE & MUJER & $\begin{array}{c}\text { CUALQUIERA } \\
\text { DE LOS DOS }\end{array}$ \\
UNA PERSONA QUE OBEDECE, HACE CASO A LO QUE DICEN & $4,6 \%$ & $11,9 \%$ & $83,5 \%$ \\
\hline UNA PERSONA QUE HACE MUCHO DEPORTE & $33,6 \%$ & $3,6 \%$ & $62,9 \%$ \\
UNA PERSONA CARINOSA & $1,7 \%$ & $36,7 \%$ & $61,6 \%$ \\
\hline UNA PERSONA QUE LE GUSTA QUE LE DIGAN COSAS BONITAS & $2,1 \%$ & $53,0 \%$ & $44,8 \%$ \\
UNA PERSONA QUE TIENE MUCHO GENIO & $33,6 \%$ & $8,3 \%$ & $58,1 \%$ \\
\hline UNA PERSONA QUE VALE PARA MANDAR Y DIRIGIR A OTROS/AS & $27,4 \%$ & $5,2 \%$ & $67,4 \%$ \\
UNA PERSONA VALIENTE, QUE SE ARRIESGA & $41,6 \%$ & $2,2 \%$ & $56,2 \%$ \\
\hline UNA PERSONA COMPRENSIVA & $5,3 \%$ & $33,1 \%$ & $61,6 \%$ \\
UNA PERSONA TIERNA & $2,4 \%$ & $43,3 \%$ & $54,4 \%$ \\
UNA PERSONA AGRESIVA & $42,4 \%$ & $2,7 \%$ & $54,8 \%$
\end{tabular}

Tabla 2. Respuestas de las niñas

\begin{tabular}{|l|c|c|c|}
\hline & HOMBRE & MUJER & $\begin{array}{c}\text { CUALQUIERA } \\
\text { DE LOS DOS }\end{array}$ \\
\hline UNA PERSONA QUE OBEDECE, HACE CASO A LO QUE DICEN & $1,3 \%$ & $14,3 \%$ & $84,4 \%$ \\
\hline UNA PERSONA QUE HACE MUCHO DEPORTE & $19,9 \%$ & $3,2 \%$ & $76,9 \%$ \\
\hline UNA PERSONA CARIÑOSA & $0,6 \%$ & $31,3 \%$ & $68,1 \%$ \\
\hline UNA PERSONA QUE LE GUSTA QUE LE DIGAN COSAS BONITAS & $0,7 \%$ & $56,7 \%$ & $42,5 \%$ \\
\hline UNA PERSONA QUE TIENE MUCHO GENIO & $23,7 \%$ & $6,6 \%$ & $69,7 \%$ \\
\hline UNA PERSONA QUE VALE PARA MANDARY DIRIGIR A OTROS/AS & $13,9 \%$ & $4,3 \%$ & $81,8 \%$ \\
\hline UNA PERSONA VALIENTE, QUE SE ARRIESGA & $25,0 \%$ & $3,7 \%$ & $71,3 \%$ \\
\hline UNA PERSONA COMPRENSIVA & $1,9 \%$ & $31,6 \%$ & $66,5 \%$ \\
\hline UNA PERSONA TIERNA & $1,8 \%$ & $38,0 \%$ & $60,2 \%$ \\
\hline UNA PERSONA AGRESIVA & $37,2 \%$ & $1,4 \%$ & $61,3 \%$ \\
\hline
\end{tabular}


El análisis de los datos de las tablas nos indican, que de forma general los rasgos de personalidad que se les ofrecieron como descriptivos, se referían de forma indistinta a hombres y mujeres, es decir, a cualquiera de los dos.

Aunque un análisis más detallado nos aporta mensajes implícitos en las respuestas de nuestros/as escolares.

Diferenciando el sexo, podemos decir que las niñas eligen, con mayor frecuencia, al asignar rasgos de la personalidad en sus respuestas a cualquiera de los dos sexos.

Sea cual sea, la descripción que elijamos, ésta no baja del $60 \%$. Si exceptuamos en ambos casos, en la respuesta de niños y niñas la característica, que parece ser muy femenina, de una persona que le gusta que le digan cosas bonitas es fundamentalmente una mujer, el 56,7\%. El 42,5\% restante va asignado a los dos.

Esta elección en la respuesta nos deja ver un mensaje implícito del aprendizaje que, tanto niños como niñas, hacen del papel de dependencia de las mujeres respecto de los demás.

Si agrupamos las características que tienen relación con el mundo afectivo, los valores de las respuestas se agrupan, tanto en niños como en las niñas, en la descripción de la mujer.

Así descripciones de persona cariñosa, comprensiva, tierna... suben en todos los casos como valores propiamente femeninos.

En cambio, aquellas actividades o actitudes que describen los atributos que tradicionalmente serían masculinos, se decantan también en la subida de los registros asignados a los hombres.

De este modo tener dotes de mando, ser una persona valiente, agresiva, o saber mandar o dirigir, parecen ser propiamente masculinos. Aunque insistimos que las niñas, parecen resistirse un poco más que los niños a ello, ellas eligen de forma más frecuente la respuesta de cualquiera de los dos. Ejemplo de ello es que los valores que registran los niños de estos apartados, es muy superior del que registran las niñas.

En lo referente al tema deportivo, las respuestas de niños y niñas son diferentes. Estos consideran que una persona que hace mucho deporte es un hombre en un porcentaje 14 puntos por encima de las niñas, que siguen considerando que una persona que hace deporte puede ser cualquiera de las dos.

En los colegios si exceptuamos la formación física educativa reglada, más conocida por gimnasia, que es igual para niños que para las niñas de la clase, la práctica deportiva que se elige tiene un marcado carácter sexista. Así los niños siguen practicando deportes "masculinos" como el fútbol, incluso de manera organizada, con campeonatos liguillas etc., y las niñas otros deportes, que podrían considerarse neutros, como el baloncesto, en el caso de practicarlos de manera organizada, lo que sucede con una frecuencia muy inferior que los chicos. 
Probablemente esto se deba a la tendencia que tienen ambos sexos a adoptar papeles y atributos masculinos como mejores y más válidos para el progreso y la adaptación al mundo actual.

Las palabras y las imágenes sexistas nos dan una visión negativa y de inferioridad de la mujer, la discriminan. Los roles y las imágenes estereotipadas, dan una visión limitada del papel de las mujeres y también de los hombres.

Lo frecuente de la distribución de papeles, hace que aún estando estereotipados, sean tomados como de la propia realidad. Como vimos en la distribución de papeles y tareas domésticas, ésta no es una distribución "natural" sino que va ligada al papel de la mujer en el desempeño de trabajos "propios de su sexo y condición".

Pregunta 2. Con frecuencia se escuchan afirmaciones sobre hombres y mujeres. ¿Cuál es tu grado de acuerdo con las que te ofrecemos a continuación?:

Tabla 3. Respuestas de los niños

\begin{tabular}{|l|c|c|c|c|}
\hline & $\begin{array}{c}\text { MUY DE } \\
\text { ACUERDO }\end{array}$ & $\begin{array}{c}\text { BASTANTE } \\
\text { DE ACUERDO }\end{array}$ & $\begin{array}{c}\text { POCO DE } \\
\text { ACUERDO }\end{array}$ & $\begin{array}{c}\text { EN } \\
\text { DESACUERDO }\end{array}$ \\
\hline $\begin{array}{l}\text { A LOS HOMBRES LES CORRESPONDE } \\
\text { TOMAR DECISIONES IMPORTANTES }\end{array}$ & $15,2 \%$ & $24,1 \%$ & $37,2 \%$ & $23,5 \%$ \\
\hline $\begin{array}{l}\text { LOS HOMBRES SON MÁS INTELIGENTES } \\
\text { QUE LAS MUJERES }\end{array}$ & $5,7 \%$ & $6,2 \%$ & $33,9 \%$ & $54,2 \%$ \\
\hline $\begin{array}{l}\text { EL SITIO NATURAL DE LAS MUJERES ES EL } \\
\text { HOGAR }\end{array}$ & $10,0 \%$ & $12,7 \%$ & $26,8 \%$ & $50,5 \%$ \\
\hline $\begin{array}{l}\text { PARA QUE UNA MUJER TRIUNFE LO MÁS } \\
\text { IMPORTANTE ES LA BELLEZA }\end{array}$ & $13,4 \%$ & $16,4 \%$ & $27,1 \%$ & $43,1 \%$ \\
\hline $\begin{array}{l}\text { ALGUNOS TRABAJOS SÓLO PUEDEN } \\
\text { HACERLOS LOS HOMBRES }\end{array}$ & $31,2 \%$ & $22,3 \%$ & $20,1 \%$ & $26,3 \%$ \\
\hline $\begin{array}{l}\text { MIENTRAS LOS NIÑOS/AS SON } \\
\text { PEQUEÑOS/AS CONVIENE QUE LA MADRE } \\
\text { NO TRABAJE FUERA DE CASA }\end{array}$ & $34,8 \%$ & $30,1 \%$ & $20,0 \%$ & $15,1 \%$ \\
\hline $\begin{array}{l}\text { LOS HOMBRES SUELEN CONDUCIR MEJOR } \\
\text { QUE LAS MUJERES }\end{array}$ & $27,2 \%$ & $17,2 \%$ & $20,6 \%$ & $35,0 \%$ \\
\hline $\begin{array}{l}\text { LAS MUJERES SON MÁS ORDENADASY } \\
\text { ORGANIZADAS QUE LOS HOMBRES }\end{array}$ & $42,5 \%$ & $28,9 \%$ & $14,4 \%$ & $14,2 \%$ \\
\hline $\begin{array}{l}\text { LOS HOMBRES SON MÁS HÁBILES A LA } \\
\text { HORA DE MANEJAR INSTRUMENTOSY } \\
\text { ARREGLAR COSAS }\end{array}$ & $41,2 \%$ & $31,9 \%$ & $15,1 \%$ & $11,7 \%$ \\
\hline LOS HOMBRES NO DEBEN LLORAR & $16,6 \%$ & $9,8 \%$ & $21,5 \%$ & $52,1 \%$ \\
\hline
\end{tabular}


Los niños y niñas aprenden desde pequeños que los papeles de los chicos y las chicas son diferentes y en muchos casos ligados al género, y no al verdadero interés que despierte en la persona. Sus decisiones y modelos en la vida van ineludiblemente condicionados por su sexo.

Tabla 4. Respuestas de las niñas

\begin{tabular}{|l|c|c|c|c|}
\hline & $\begin{array}{c}\text { MUY DE } \\
\text { ACUERDO }\end{array}$ & $\begin{array}{c}\text { BASTANTE DE } \\
\text { ACUERDO }\end{array}$ & $\begin{array}{c}\text { POCO DE } \\
\text { ACUERDO }\end{array}$ & $\begin{array}{c}\text { EN } \\
\text { DESACUERDO }\end{array}$ \\
\hline $\begin{array}{l}\text { A LOS HOMBRES LES } \\
\text { CORRESPONDE TOMAR } \\
\text { DECISIONES IMPORTANTES }\end{array}$ & $6,8 \%$ & $12,8 \%$ & $37,5 \%$ & $42,9 \%$ \\
\hline $\begin{array}{l}\text { LOS HOMBRES SON MÁS } \\
\text { INTELIGENTES QUE LAS } \\
\text { MUJERES }\end{array}$ & $1,0 \%$ & $2,1 \%$ & $13,0 \%$ & $83,9 \%$ \\
\hline $\begin{array}{l}\text { EL SITIO NATURAL DE LAS } \\
\text { MUJERES ES EL HOGAR }\end{array}$ & $5,5 \%$ & $7,2 \%$ & $16,5 \%$ & $70,8 \%$ \\
\hline $\begin{array}{l}\text { PARA QUE UNA MUJER } \\
\text { TRIUNFE LO MÁS IMPORTANTE } \\
\text { ES LA BELLEZA }\end{array}$ & $5,8 \%$ & $10,3 \%$ & $27,6 \%$ & $56,4 \%$ \\
\hline $\begin{array}{l}\text { ALGUNOS TRABAJOS SÓLO } \\
\text { PUEDEN HACERLOS LOS } \\
\text { HOMBRES }\end{array}$ & $12,7 \%$ & $17,6 \%$ & $28,5 \%$ & $41,2 \%$ \\
\hline $\begin{array}{l}\text { MIENTRAS LOS NIÑOS/AS SON } \\
\text { PEQUENNOS/AS CONVIENE QUE } \\
\text { LA MADRE NO TRABAJE FUERA } \\
\text { DE CASA }\end{array}$ & $27,0 \%$ & $30,2 \%$ & $24,9 \%$ & $17,9 \%$ \\
\hline $\begin{array}{l}\text { LOS HOMBRES SUELEN } \\
\text { CONDUCIR MEJOR QUE LAS } \\
\text { MUJERES }\end{array}$ & $5,7 \%$ & $6,8 \%$ & $17,6 \%$ & $69,9 \%$ \\
\hline $\begin{array}{l}\text { LAS MUJERES SON MÁS } \\
\text { ORDENADAS Y ORGANIZADAS } \\
\text { QUE LOS HOMBRES }\end{array}$ & $50,7 \%$ & $31,6 \%$ & $10,4 \%$ & $7,3 \%$ \\
\hline $\begin{array}{l}\text { LOS HOMBRES SON MÁS } \\
\text { HÁBILES A LA HORA DE } \\
\text { MANEJAR INSTRUMENTOSY } \\
\text { ARREGLAR COSAS }\end{array}$ & $24,1 \%$ & $31,5 \%$ & $25,6 \%$ & $18,9 \%$ \\
\hline $\begin{array}{l}\text { LOS HOMBRES NO DEBEN } \\
\text { LLORAR }\end{array}$ & $5,6 \%$ & $3,6 \%$ & $15,5 \%$ & $75,3 \%$ \\
\hline
\end{tabular}


En este apartado, que presenta afirmaciones muy relacionadas con los roles, desempeñados por los hombres y las mujeres, las respuestas y los resultados que analizamos a continuación reflejan la clara relación que los estereotipos de género tienen con los mismos.

Como en el caso de la pregunta anterior, sobre atributos, las respuestas de las niñas, son marcadamente más igualitarias. La mayoría de sus respuestas van tendentes a estar en desacuerdo con las afirmaciones estereotipadas que se presentan. En algunos casos la diferencia, con respecto a las respuestas de los niños, duplica el desacuerdo, así mientras el 39,3\% de los escolares masculinos afirma estar de acuerdo o muy de acuerdo con la afirmación: "a los hombres les corresponde tomar decisiones importantes" el 80,4\% de las escolares está en total desacuerdo. Afortunadamente cada vez más mujeres van abandonado su papel secundario asumiendo la responsabilidad que conlleva el tomar decisiones importantes.

Sin embargo, es muy significativo que el grado de similitud que alcanza una respuesta, tanto para niños como para niñas, sea igual en dos afirmaciones concretas: la referida al papel de la mujer como madre y la dirigida a la habilidad para manejar instrumentos y arreglar cosas.

Volvemos a tener que preguntarnos. ¿Hay auténtica participación compartida entre hombres y mujeres, padres y madres, en las tareas domésticas y en el cuidado y crianza de los hijos e hijas?

Parece claro que no. La asimilación del papel de la mujer en el cuidado y atención de los hijos e hijas, les hace ver con demasiada evidencia la conveniencia de la dedicación exclusiva durante el periodo en el que son pequeños/as. Lo que indica de nuevo, que la mujer, pese a su incorporación creciente al mercado laboral y al mundo profesional, suele tener trabajos de carácter secundario, probablemente complementarios a los del hombre. Trabajos que pueden ser sometidos a renuncia, abandono o excedencia durante la fase de crianza.

Es difícil pensar, que tanto niños como niñas no asimilen lo estereotipado del papel, de la casi exclusividad, de esta "tarea" para las mujeres y del arreglo de cosas en el hogar por parte de los hombres.

Desde la infancia, los niños y las niñas aprenden sus papeles jugando y los juegos y la oferta de los juguetes y su publicidad, es marcadamente sexista.

Jugar a las muñecas proporciona experiencias y destrezas relacionadas con el cuidado de los bebés. Fomentando el posterior modelo, equívoco por otro lado, de que "todas las mujeres son madres". A los niños por el contrario se les ofertan juguetes que desarrollan habilidades, de ahí que se asimile la mayor habilidad instrumental a los chicos. 
Pregunta 3. Lee las siguientes frases y dinos si estás muy de acuerdo, de acuerdo, en desacuerdo o muy en desacuerdo.

Tabla 5. Respuestas de los niños

\begin{tabular}{|c|c|c|c|c|}
\hline & $\begin{array}{l}\text { MUY DE } \\
\text { ACUERD } \\
\quad 0\end{array}$ & $\begin{array}{c}\text { DE } \\
\text { ACUERDO }\end{array}$ & $\begin{array}{c}\text { EN } \\
\text { DESACUERD } \\
0\end{array}$ & $\begin{array}{c}\text { MUY EN } \\
\text { DESACUERD } \\
0\end{array}$ \\
\hline $\begin{array}{l}\text { PARA QUE UNA FAMILIA FUNCIONE BIEN } \\
\text { HAY QUE HACER LO QUE DIGA EL PADRE }\end{array}$ & $6,7 \%$ & $14,4 \%$ & $46,3 \%$ & $32,6 \%$ \\
\hline $\begin{array}{l}\text { UNA MUJER NO DEBE LLEVAR LA } \\
\text { CONTRARIA A SU MARIDO }\end{array}$ & $6,0 \%$ & $11,3 \%$ & $41,3 \%$ & $41,4 \%$ \\
\hline $\begin{array}{l}\text { LOS NIÑOS PUEDEN LLEGAR MÁS } \\
\text { TARDE A CASA QUE LAS NINIAS }\end{array}$ & $10,6 \%$ & $13,6 \%$ & $38,1 \%$ & $37,7 \%$ \\
\hline $\begin{array}{l}\text { LA MUJER PUEDE TRABAJAR FUERA DE } \\
\text { CASA AUNQUE EL MARIDO NO LO VEA } \\
\text { BIEN }\end{array}$ & $39,2 \%$ & $35,1 \%$ & $15,2 \%$ & $10,5 \%$ \\
\hline $\begin{array}{l}\text { LA MUJER TIENE QUE HACER LAS } \\
\text { TAREAS DEL HOGAR }\end{array}$ & $9,2 \%$ & $26,2 \%$ & $39,8 \%$ & $24,9 \%$ \\
\hline $\begin{array}{l}\text { UNA MUJER ESTÁ CAPACITADA PARA } \\
\text { TRABAJAR COMO UN HOMBRE }\end{array}$ & $42,3 \%$ & $32,5 \%$ & $17,4 \%$ & $7,8 \%$ \\
\hline $\begin{array}{l}\text { LOS PROFESORES/AS TRATAN A LOS } \\
\text { CHICOS DE FORMA DIFERENTE A LAS } \\
\text { CHICAS }\end{array}$ & $17,7 \%$ & $21,0 \%$ & $34,0 \%$ & $27,2 \%$ \\
\hline $\begin{array}{l}\text { EN LOS LIBROS QUE ESTUDIAMOS } \\
\text { PARECE QUE CASI TODOS LOS } \\
\text { AVANCES DE LA HUMANIDAD LOS HAN } \\
\text { HECHO LOS HOMBRES }\end{array}$ & $21,6 \%$ & $40,0 \%$ & $26,1 \%$ & $12,3 \%$ \\
\hline $\begin{array}{l}\text { LOS CHICOS DE MI CLASE LO QUE MÁS } \\
\text { VALORAN DE MIS COMPAÑERAS ES QUE } \\
\text { SEAN GUAPAS Y SIMPÁTICAS }\end{array}$ & $37,6 \%$ & $36,6 \%$ & $17,2 \%$ & $8,6 \%$ \\
\hline $\begin{array}{l}\text { A LAS CHICAS LOS PROFESORES/AS } \\
\text { LAS SUELEN ALABAR POR SER DÓCILES } \\
\text { Y EDUCADAS }\end{array}$ & $24,1 \%$ & $33,4 \%$ & $26,9 \%$ & $15,6 \%$ \\
\hline
\end{tabular}


Proponer un tipo de juegos más igualitario, para el aprendizaje de nuevos modelos no tradicionales, no ha sido suficiente, porque a lo que fundamentalmente se ha tendido y se sigue tendiendo es que las chicas asimilen los papeles de los chicos, y no al contrario. No es un planteamiento "perverso" proponer que los chicos jueguen a las muñecas, bien al contrario es la forma de no fomentar y reproducir modelos estereotipados.

La única frase en la que el grado de acuerdo con la afirmación es superior en las niñas que en los niños, es en las mujeres que son más ordenadas y organizadas que los hombres.

Esta respuesta tiene mucho que ver con la imagen que las niñas tienen de sí mismas, a través de los mensajes que reciben y que asimilan como una realidad propia.

No sabemos qué grado de estereotipo tiene y aunque sea de carácter positivo, el atributo de orden y organización, parece muy claro que tiene mucha vinculación con el carácter doméstico de orden y organización de los espacios, de su habitación, de sus cosas, sus juguetes, su pupitre, su aula.

De cualquier modo, los estereotipos teniendo el carácter negativo o positivo, van muy asociados a actitudes prejuiciosas y desgraciadamente, en muchos casos, a comportamientos discriminatorios.

Porque el orden dominante, sigue siendo el orden masculino, el estereotipo de la diferencia sigue actuando, aunque sea a niveles inconscientes.

El tiempo asignado a la vida social fuera del hogar está claramente diferenciado por el sexo de los/as escolares, mientras que a los chicos se les permite llegar más tarde a casa que a las chicas, a éstas se les restringe el horario.

La hora de llegar a casa por la noche es un indicador de esta diferenciación en el trato de los padres hacia sus hijos e hijas, y la mayor restricción hacia las mujeres lo que marca la diferencia entre lo que se considera oportuno y perteneciente a uno u otro sexo. Esta actitud discriminatoria no se corresponde con los deseos de los niños y niñas entrevistados/as ya que la gran mayoría de ellos/as están a favor de que las niñas puedan regresar a casa a las mismas horas que los niños.

Lógicamente hay muchas más niñas que niños que defienden la igualdad de horarios para los dos sexos, actitud que se ve acrecentada con la edad. Este hecho está provocando determinados tipos de presión de las hijas hacia los padres con vistas a conseguir una ampliación y equiparación de horario. Como resultado de estas actitudes las chicas están consiguiendo lo que se proponen, aunque no son raros los casos en los que los padres siguen adoptando en el horario exigencias distintas para 
uno u otro sexo, lo que provoca no pocos problemas y ciertas situaciones paradójicas al tener que regresar antes a casa hijas con mayor edad que sus hermanos.

Tabla 6. Respuestas de las niñas

\begin{tabular}{|c|c|c|c|c|}
\hline & $\begin{array}{c}\text { MUY DE } \\
\text { ACUERDO }\end{array}$ & $\begin{array}{c}\text { DE } \\
\text { ACUERDO }\end{array}$ & $\begin{array}{c}\text { EN } \\
\text { DESACUERDO } \\
\end{array}$ & $\begin{array}{c}\text { MUY EN } \\
\text { DESACUERDO }\end{array}$ \\
\hline $\begin{array}{l}\text { PARA QUE UNA FAMILIA FUNCIONE } \\
\text { BIEN HAY QUE HACER LO QUE DIGA } \\
\text { EL PADRE }\end{array}$ & $2,4 \%$ & $6,3 \%$ & $41,6 \%$ & $49,8 \%$ \\
\hline $\begin{array}{l}\text { UNA MUJER NO DEBE LLEVAR LA } \\
\text { CONTRARIA A SU MARIDO }\end{array}$ & $2,3 \%$ & $7,3 \%$ & $32,3 \%$ & $58,1 \%$ \\
\hline $\begin{array}{l}\text { LOS NIÑOS PUEDEN LLEGAR MÁS } \\
\text { TARDE A CASA QUE LAS NIÑAS }\end{array}$ & $2,0 \%$ & $3,5 \%$ & $26,5 \%$ & $68,0 \%$ \\
\hline $\begin{array}{l}\text { LA MUJER PUEDE TRABAJAR FUERA } \\
\text { DE CASA AUNQUE EL MARIDO NO LO } \\
\text { VEA BIEN }\end{array}$ & $49,6 \%$ & $33,9 \%$ & $10,4 \%$ & $6,2 \%$ \\
\hline $\begin{array}{l}\text { LA MUJER TIENE QUE HACER LAS } \\
\text { TAREAS DEL HOGAR }\end{array}$ & $4,9 \%$ & $15,8 \%$ & $39,6 \%$ & $39,8 \%$ \\
\hline $\begin{array}{l}\text { UNA MUJER ESTÁ CAPACITADA } \\
\text { PARA TRABAJAR COMO UN HOMBRE }\end{array}$ & $53,8 \%$ & $27,4 \%$ & $11,7 \%$ & $7,1 \%$ \\
\hline $\begin{array}{l}\text { LOS PROFESORES/AS TRATAN A } \\
\text { LOS CHICOS DE FORMA DIFERENTE } \\
\text { A LAS CHICAS }\end{array}$ & $4,6 \%$ & $14,4 \%$ & $41,6 \%$ & $39,4 \%$ \\
\hline $\begin{array}{l}\text { EN LOS LIBROS QUE ESTUDIAMOS } \\
\text { PARECE QUE CASI TODOS LOS } \\
\text { AVANCES DE LA HUMANIDAD LOS } \\
\text { HAN HECHO LOS HOMBRES }\end{array}$ & $12,7 \%$ & $39,3 \%$ & $29,8 \%$ & $18,2 \%$ \\
\hline $\begin{array}{l}\text { LOS CHICOS DE MI CLASE LO QUE } \\
\text { MÁS VALORAN DE MIS COMPAÑERAS } \\
\text { ES QUE SEAN GUAPASY } \\
\text { SIMPÁTICAS }\end{array}$ & $33,2 \%$ & $38,7 \%$ & $18,0 \%$ & $10,1 \%$ \\
\hline $\begin{array}{l}\text { A LAS CHICAS LOS PROFESORES/AS } \\
\text { LAS SUELEN ALABAR POR SER } \\
\text { DÓCILES Y EDUCADAS }\end{array}$ & $17,3 \%$ & $36,2 \%$ & $30,9 \%$ & $15,6 \%$ \\
\hline
\end{tabular}


Gráfico 1. Para que una familia funcione bien hay que hacer lo que diga el padre

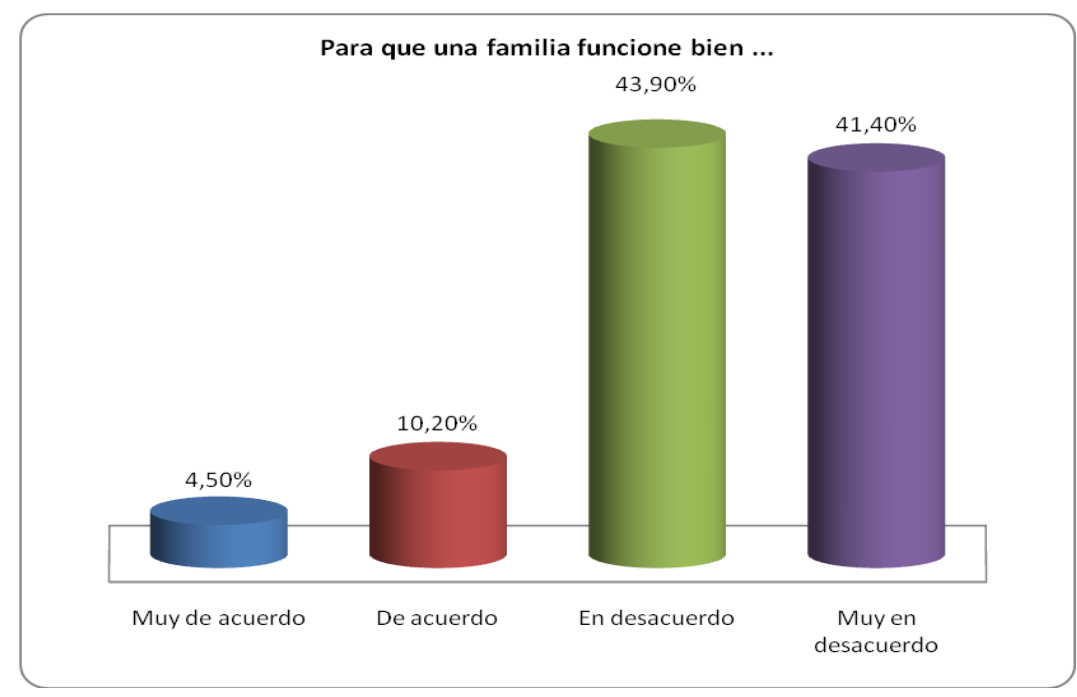

Un diálogo sincero entre los padres y las hijas sobre todo, podría llevar a una serie de pactos que conllevarán un trato más igualitario con relación a sus hermanos varones, lo que no significa que cualquier petición de los hijos e hijas deba ser aceptada sin más.

Gráfico 2. Los niños pueden llegar más tarde a casa que las niñas

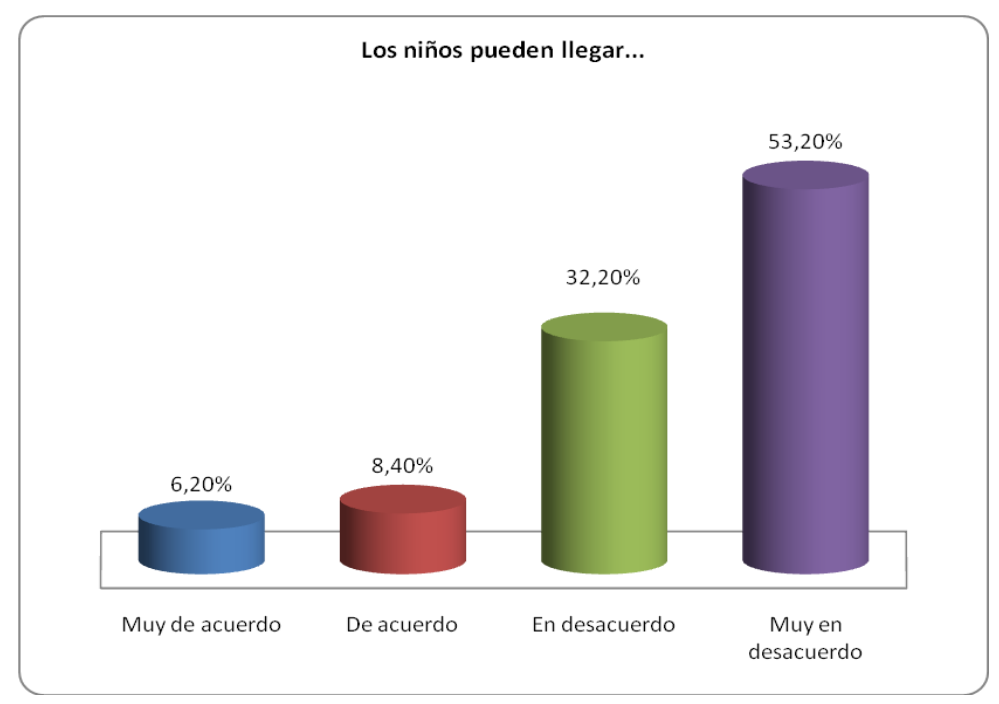


Gráfico 3. La mujer puede trabajar fuera de casa aunque el marido no lo vea bien

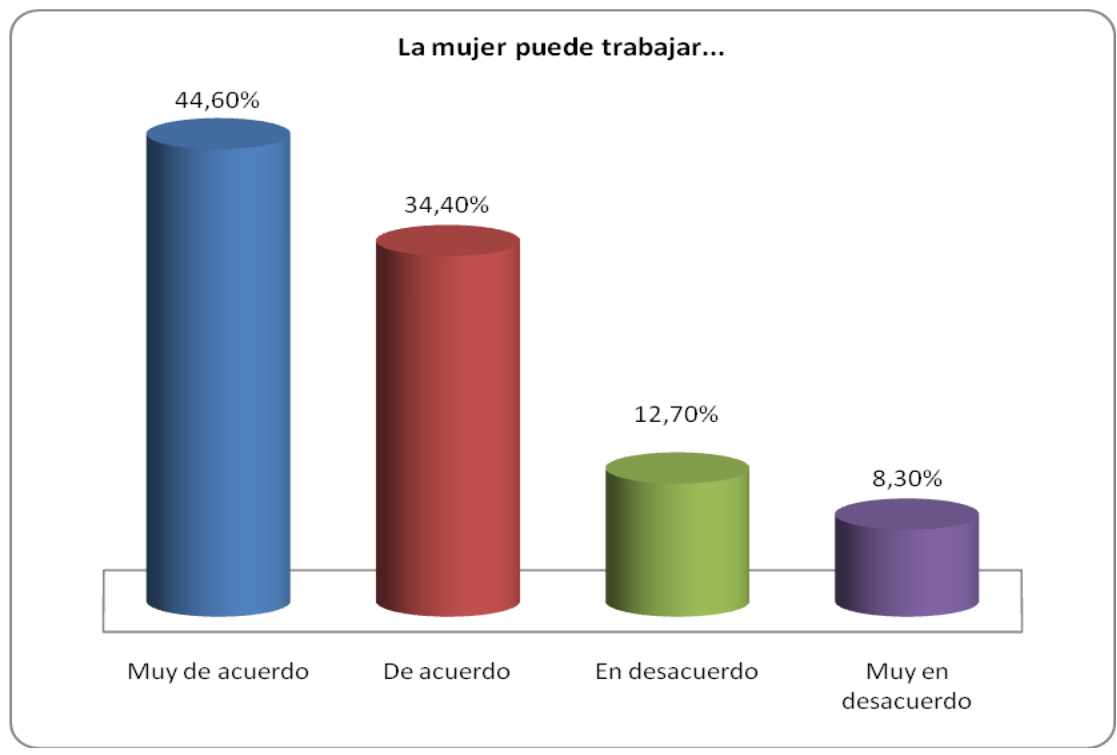

En otros tiempos no estaba bien visto que la mujer trabajara fuera de casa sobre todo si no tenía el permiso de su marido. Esto provocaba en no pocos casos una dependencia de la mujer respecto del esposo y una falta de autoestima.

En el momento actual, sobre todo en las sociedades urbanas, la entrada de la mujer en el mundo del trabajo se ha generalizado, no obstante en sociedades rurales, como ocurre con una buena parte de la extremeña, encontramos todavía muchas mujeres que se dedican a "sus labores", afortunadamente esta situación comienza a cambiar y lo hará más en el futuro, sobre todo porque la actitud de las nuevas generaciones, con mayor nivel de estudios que sus progenitores, manifiesta ya su clara disposición al trabajo extradoméstico de las mujeres sin que para ello tengan que pedir permiso a sus respectivos maridos, así lo manifiesta el $83,5 \%$ de las niñas entrevistadas y el $74,3 \%$ de los niños entrevistados

La actitud que manifiesta el alumnado extremeño pronostica profundos cambios en la estructura familiar, semejantes a los que se vienen produciendo en las sociedades modernas. A pesar de todo aún quedan pequeños núcleos, sobre todo en zonas rurales, que siguen viendo lógico el sometimiento de la mujer a su marido, muy probablemente porque lo estén viviendo en casa.

La escuela debe intervenir en estos casos para orientar la conciencia de las niñas $\mathrm{y}$, sobre todo de los niños, hacia posturas más igualitarias. 
Gráfico 4. La mujer tiene que hacer las tareas del hogar

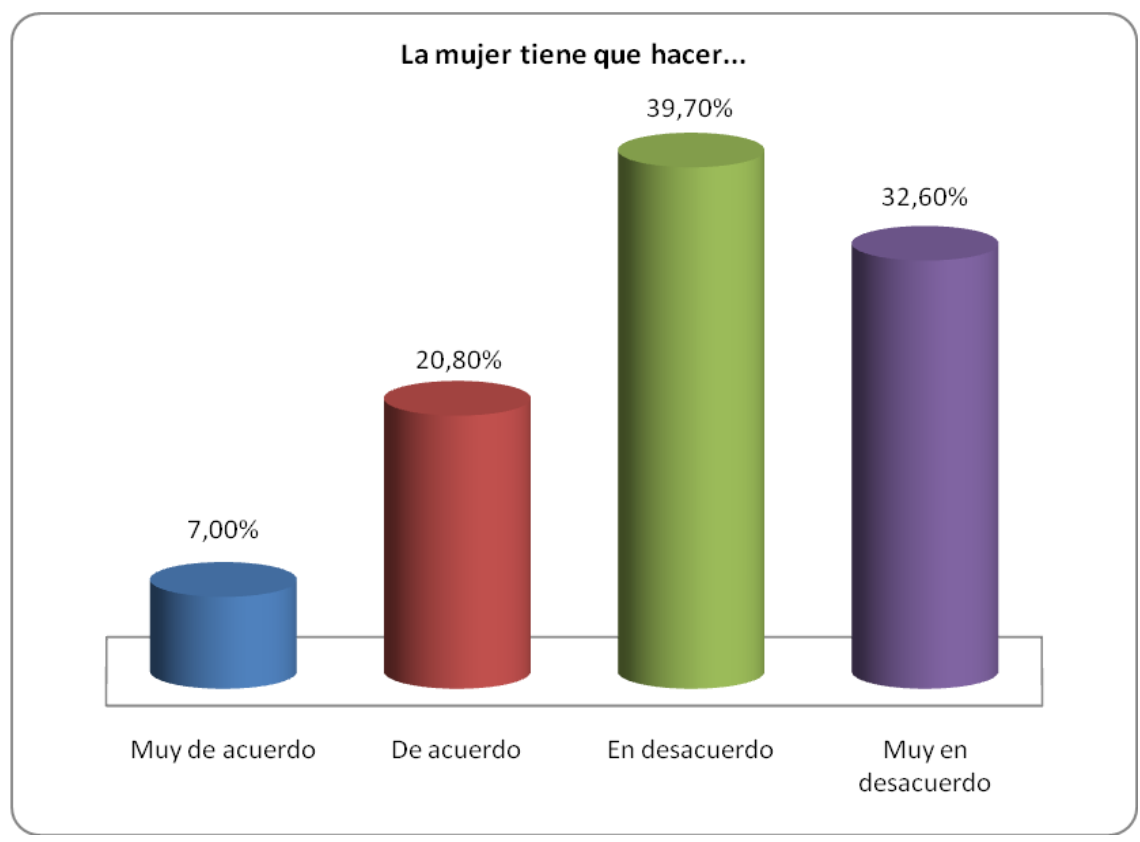

Las tareas domésticas son uno de los puntos donde se articula con mayor fuerza la diferenciación de roles dentro del hogar.

El estudio indica que continúan siendo las mujeres las que con mayor frecuencia asumen y realizan dichas labores, y que se continúa atribuyendo socialmente a las mujeres el desarrollo de esos trabajos.

Las familias más tradicionales potencian esa diferenciación que las chicas en el transcurso de su desarrollo aprenden y practican, porque en general, en esa sociedad, son las mujeres las encargadas de realizar esos trabajos.

Un gran número de escolares varones 35,4\% identifica las tareas del hogar con la mujer, situación que se invierte cuando las que contestan son las chicas. Entre las niñas sólo un $20 \%$ acepta el rol doméstico adscrito al sexo, mientras que el $80 \%$ restante está en desacuerdo.

La aceptación de las tareas del hogar, al menos de palabra, aumenta con la edad del alumnado entrevistado, respuesta que no se corresponde con su actuación ya que disminuye su grado de colaboración con el paso de los años. Esta postura contradictoria entre lo que se dice y lo que se hace traerá graves problemas entre las futuras parejas si previamente no la corregimos desde el ámbito familiar y escolar. 
Sorprende la rotundidad de la respuesta frente a otras que han sido más comedidas. Hay, en general, una actitud positiva mayoritaria respecto a la capacitación de las mujeres para desempeñar en el mundo laboral cualquier tipo de trabajo. Así lo confirman un $75 \%$ de chicos y un $81 \%$ de chicas.

Gráfico 5. Una mujer está capacitada para trabajar como un hombre

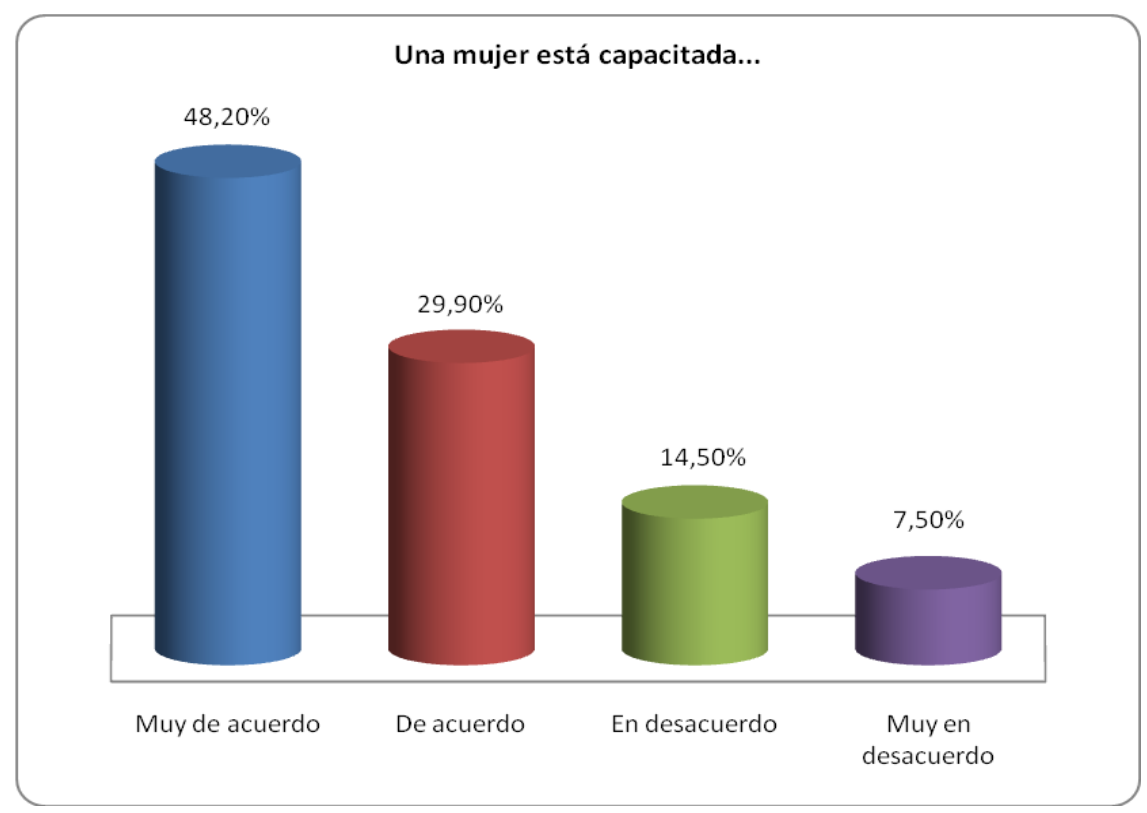

La chicas eligen más la alternativa estar muy de acuerdo con la propuesta presentada frente al de acuerdo de los chicos, por tanto, otra vez, la variable sexo resulta clave a la hora de constatar las actitudes frente a una cuestión determinada.

Hay coincidencia de criterios entre los colegios públicos y privados, aunque menos escolares del privado en relación con el público secundan la primera opción.

Si tomamos como variable la residencia, en todas las áreas se aprecia la misma concepción social, sin embargo, en el área urbana un mayor porcentaje de escolares se sitúan en la primera opción de estar muy de acuerdo con la afirmación que la mujer está capacitada para trabajar como un hombre.

Los mayores desacuerdos a la pregunta planteada corresponden a las muestras recogidas en zonas rurales, donde la mayoría de madres del alumnado entrevistado se dedican a sus labores, lo que influye, sin duda alguna, en las respuestas de niños y niñas. 
Gráfico 6. Los profesores/as tratan a los chicos de forma diferente que a las chicas

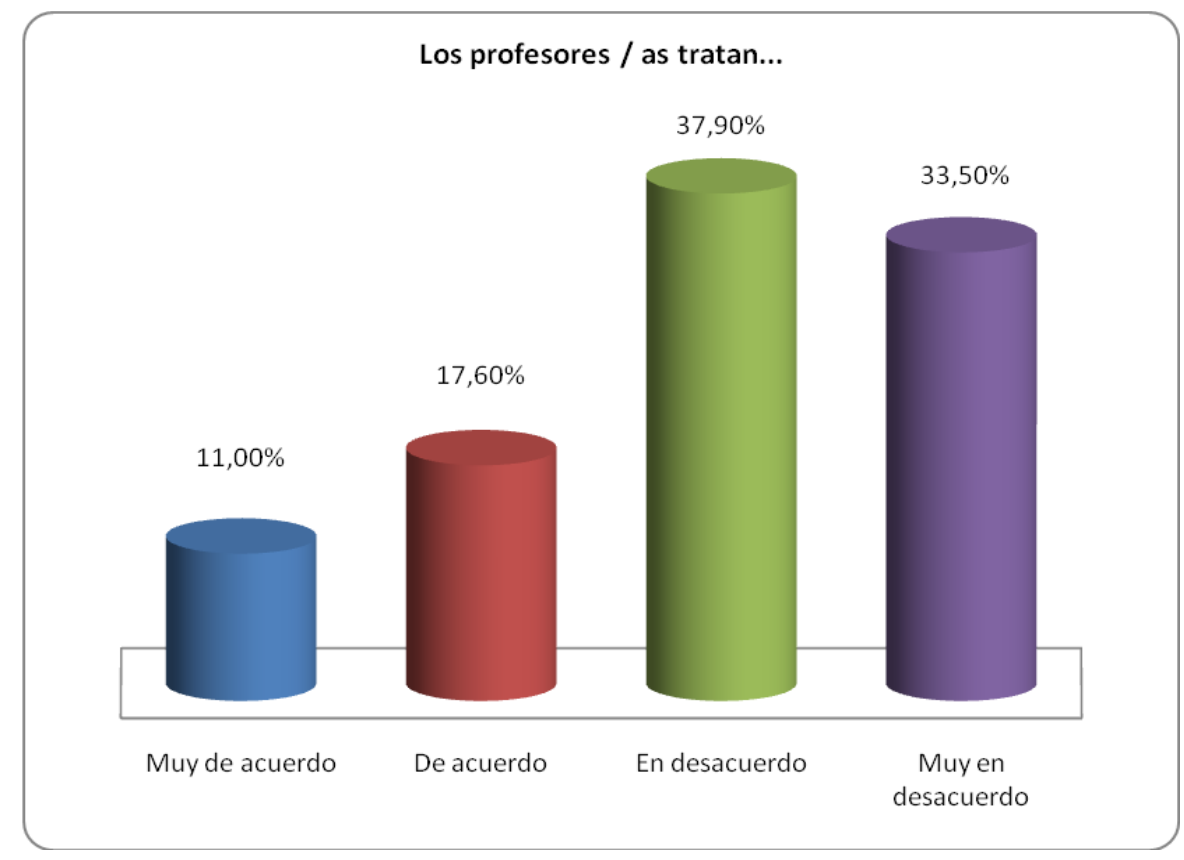

Gráfico 7. En los libros parece que todos los avances de la humanidad los han hecho los hombres

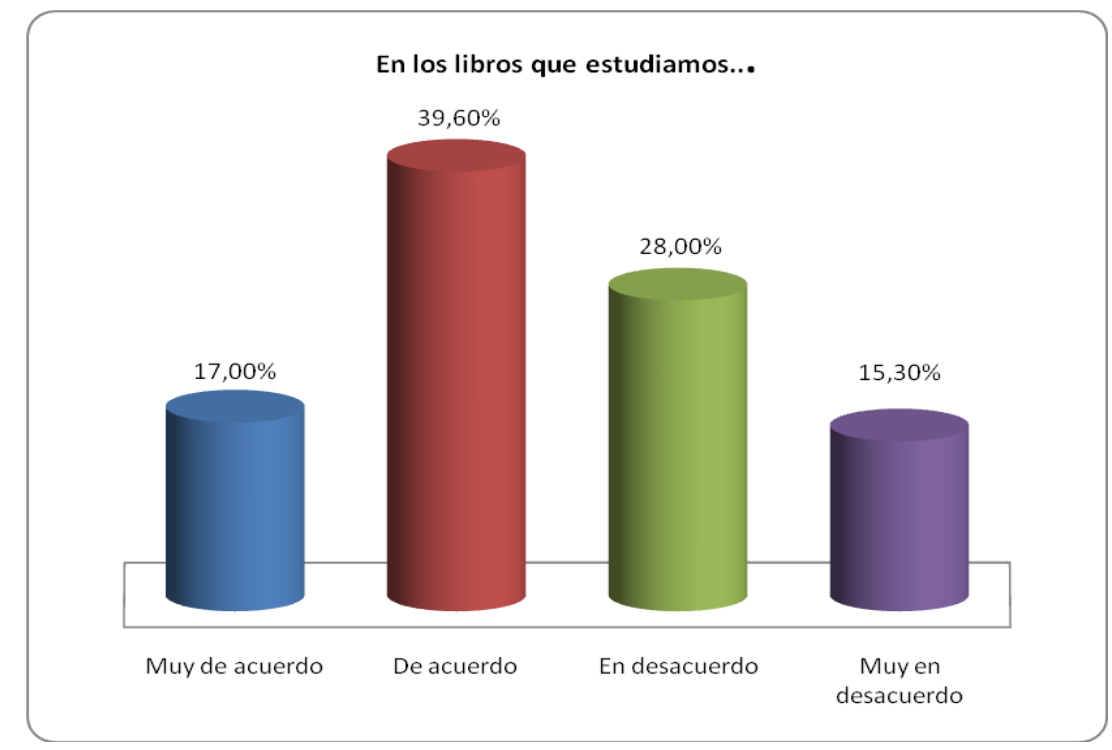


Mucha gente piensa que los libros de texto actuales ya no establecen discriminaciones entre hombres y mujeres, pero los datos de investigaciones recientes nos dicen que esto todavía no es una realidad.

Los libros de texto junto con otros recursos didácticos que se utilizan en las aulas, son elementos clave para conseguir los objetivos en cada etapa educativa.

La adecuación de los libros de texto a cada momento y situación requiere que éstos recojan las transformaciones de la sociedad, protagonizadas por hombres y mujeres, dando un tratamiento equilibrado a su presencia, protagonismo y aportaciones. Desde la etapa infantil los niños y las niñas se van familiarizando con unas imágenes concretas, y parte de su mundo se va conformando según esas imágenes. Por eso, es imprescindible que las historias que cuentan y la forma de tratarlas, puedan responder a las inquietudes y expectativas de ambos sexos sin discriminaciones.

Cuando se aborda la historia, se sigue obviando que es fundamental que la humanidad es sexuada y que está formada por mujeres y hombres. La historia sigue estando explicada desde un solo punto de vista: el masculino. Las aportaciones de las mujeres siguen sin ser consideradas importantes en el devenir de los acontecimientos, apareciendo sólo en escasas situaciones y relegadas a papeles secundarios. El protagonismo masculino es casi absoluto. Se continúan reproduciendo epígrafes como:"Los hombres como protagonistas de la historia", "los hombres cambian el mundo" y otros ejemplos similares. El papel que se asigna a las mujeres aparece infravalorado, o limitado a roles carentes de decisión y responsabilidad, como personajes sumisos y receptores frente al poder y la acción masculina.

En cuanto a la ciencia y la técnica, son ámbitos que aparecen de forma predominante como masculinos. La ciencia y la técnica parecen esferas reservadas en exclusiva para los hombres, donde sólo ellos pueden desarrollarlas, de hecho, los libros así lo representan. Las mujeres aparecen, en la mayoría de los casos, como receptoras y ajenas a la creación e iniciativa en el mundo de la ciencia y de la técnica.

Una vez expuesto lo que muchos/as investigadores/as han descubierto en los libros escolares nos interesaba conocer la opinión al respecto de los propios interesados/as. ¿Son conscientes los niños y niñas de los diversos grados de sexismo que aparecen en los libros escolares? Depende sobre todo de su edad, mientras que el $46 \%$ del alumnado de 10 a 11 años piensa que los libros que estudian parece que casi todos los avances de la humanidad los han hecho los hombres el 64,5\% del alumnado de 16 a 17 años piensa lo mismo. Seguramente, al poseer los de más edad una mayor maduración mental, unida a una más amplia instrucción les permite descubrir que los libros no dicen toda la verdad sobre los avances de la humanidad, resaltando en 
exceso lo que han hecho los hombres, y dejando a un lado cuando no olvidando lo que han desarrollado las mujeres.

En las clases de los mayores registramos comentarios de este tipo:" Lo que pasa es que hasta este siglo, dice una chica de $4^{\circ}$ de ESO, las mujeres habían escrito muy poco. La historia la han escrito los hombres y han dicho lo que les parecía bien". Visión diferente es la manifestada por un chico de $6^{\circ}$ de primaria:"... pues claro que tiene que ser así, ¿quién ha inventado el tren, el coche, la luz y casi todas las máquinas que hay? Pues el hombre... ¿o no? Por eso lo dicen así los libros “.

La LOE incorpora el principio de igualdad de oportunidades y no discriminación por razón de sexo en los libros de texto, pero como bien dice el refrán: "Del dicho al hecho va un buen trecho". Tratar de suprimirlo es tarea de los educadores y educadoras de todos los niveles.

Gráfico 8. Los chicos de mi clase lo que más valoran de mis compañeras es que sean guapas y simpáticas

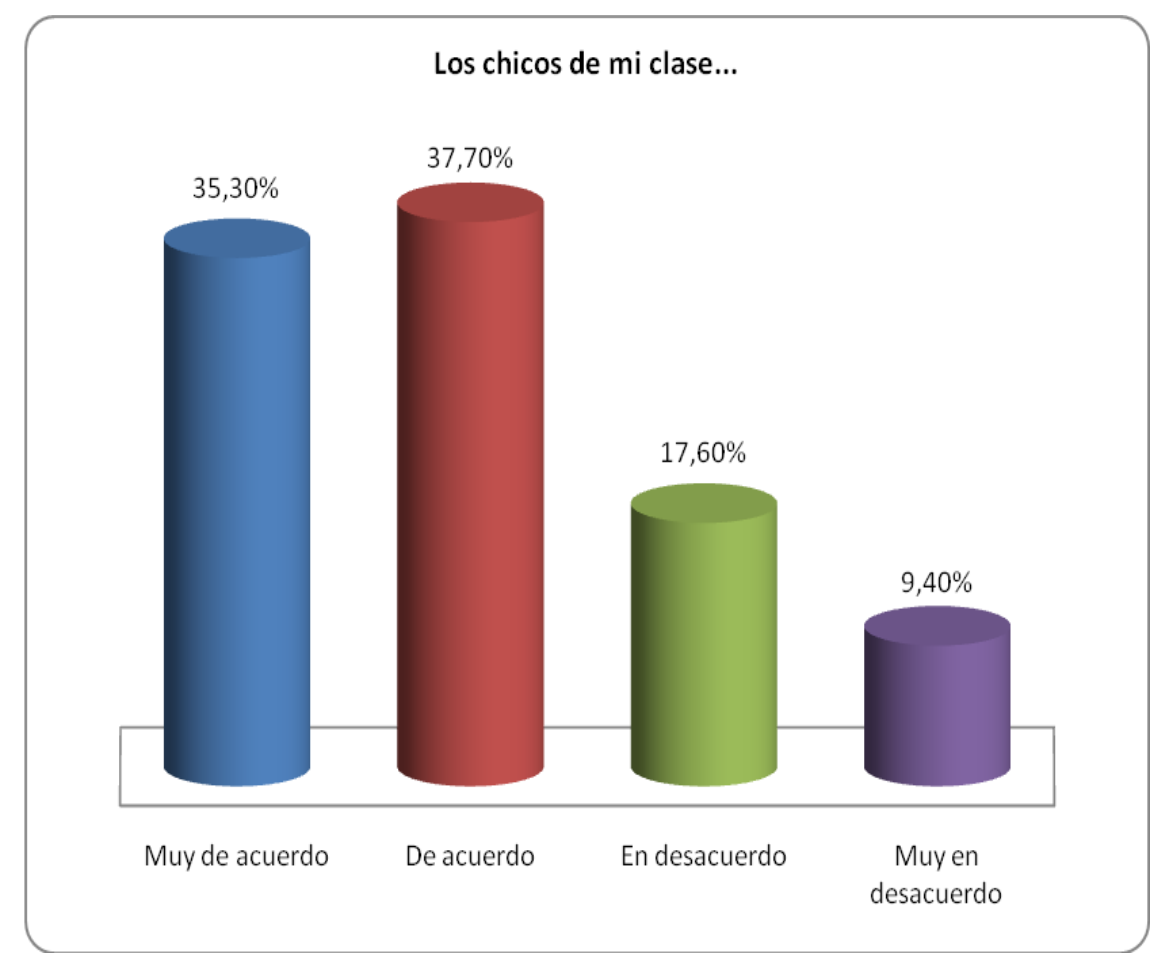


Tradicionalmente se venía considerando que la función primordial de la mujer en la vida era encontrar marido y ser madre; a tal efecto, desde pequeñita se la preparaba para desempeñar su futuro rol con las mayores posibilidades de éxito. La tradición sigue viva, aunque, los criterios de interpretación han cambiado. Los encantos femeninos, belleza y simpatía, siguen siendo fundamentales.

El $74 \%$ de chicos valoran mucho que sus compañeras sean guapas y simpáticas, en casi idéntica proporción (72\%) lo hacen las chicas. Con la entrada en la adolescencia se valoran en las chicas, mucho más que en otras edades, las cualidades de belleza y simpatía, lo que provoca que ellas cuiden más el físico que sus compañeros para así resultar más atractivas. Toman modelos de artistas, a veces de una forma desproporcionada y peligrosa.

Enfermedades como la anorexia pueden entenderse en el contexto que estamos hablando. Una educación adecuada puede ayudarles a desarrollar comportamientos más equilibrados.

Gráfico 9. A las chicas los profesores las suelen alabar por ser dóciles y educadas

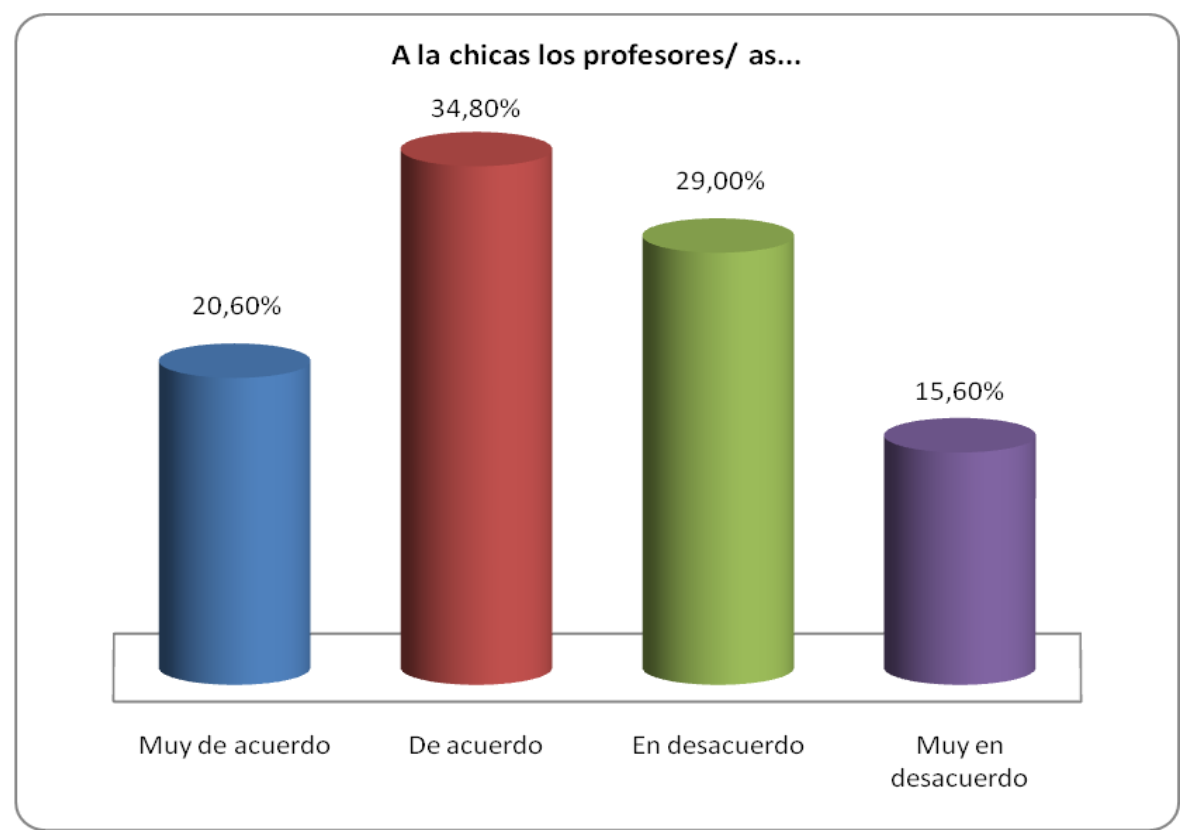


Los entrevistados varones, en su gran mayoría, aseguran que las buenas maneras y la aquiescencia son las virtudes que el profesorado más pondera en las chicas. La visión de las chicas es bastante similar a la manifestada por sus compañeros.

Al profesorado suelen plantearle menos problemas las chicas que los chicos, son más ordenadas, más metódicas en la realización y presentación de trabajos, menos bulliciosas ...; todas estas pautas de acción facilitan la labor didáctica y el profesorado ha de reconocerlo, básicamente para motivar al resto de alumnado; no obstante, en muchas ocasiones se genera el fenómeno contrario, los celos.

Recordamos un comentario de un chico de $6^{\circ}$ de Primaria, que llamaba a las chicas "mosquitas muertas" ... que, parecían "no haber roto un plato" ..., así conseguían mejores notas. Suelen opinar de esta guisa aquellos alumnos que por su dinamismo e inquietud están siempre planteando problemas de orden en la clase. Son los típicos "rabo de lagartija", para los que en la mayoría de las ocasiones la paciencia para escuchar y el sentido de responsabilidad están ausentes en sus conductas cotidianas; este chico sentía celos por el buen hacer de su compañera.

\section{CONCLUSIONES}

A continuación señalamos algunos de los aspectos más destacables del apartado analizado, sobre los estereotipos y actitudes sexistas:

1. Las niñas, con mayor frecuencia, eligen a cualquiera de los dos sexos al asignar rasgos de la personalidad en sus respuestas.

2. En las características o descripciones tradicionalmente femeninas: cariñosa, comprensiva, tierna, los valores de las respuestas se agrupan, tanto en los niños como en las niñas, en la descripción de la mujer.

3. En las características, actividades o actitudes como valiente, agresiva, o saber mandar o dirigir, que describen los atributos que tradicionalmente se consideran masculinos, los chicos se decantan en la respuesta de hombre. En menor medida lo hacen las niñas, la mitad de veces que los niños.

4. En las afirmaciones, muy relacionadas con los papeles, que desempeñan los hombres y las mujeres, las respuestas y los resultados analizados reflejan la clara relación que los estereotipos de género tienen con los roles. 
5. La asimilación del papel de la mujer en el cuidado y atención de los hijos e hijas, les hace ver con demasiada evidencia, la conveniencia de la dedicación exclusiva durante el periodo en el que son pequeños/as. Esto es igual para ambos sexos.

6. Las niñas tienen una imagen de sí mismas y de las mujeres en general, como más ordenadas y organizadas que los hombres. Única frase en la que el grado de acuerdo con la afirmación es superior en las niñas que en los niños.

7. La asunción de las afirmaciones estereotipadas está íntimamente relacionada con los roles tradicionales y previsiblemente asignados a los diferentes sexos. Por ello, el grado de acuerdo o no con afirmaciones que se escuchan, está muy relacionado con los papeles o roles que se determinan de forma diferencial a los sexos.

\section{BIBLIOGRAFÍA}

DÍAZ-AGUADO, Mª. J. (2006): Del acoso escolar a la cooperación en las aulas, Madrid, Pearson Educación/Prentice Hall.

DÍAZ-AGUADO, $\mathrm{M}^{\mathrm{a}}$. J. et al. (2002): Prevenir la violencia contra las mujeres: construyendo la igualdad, Madrid, Ministerio de Trabajo y Asuntos Sociales.

GIMENO SACRISTÁN, J. (2002): Educar y convivir en la cultura global, Madrid, Morata.

GONZÁLEZ POZUELO, F. (1999): Escolares extremeños del 2000, Badajoz, Junta de Extremadura.

MAÑERU MÉNDEZ, A. y RUBIO HERRAEZ, E. (1992): Educación para igualdad de oportunidades de ambos sexos. Transversales, Madrid, Ministerio de Educación y Ciencia.

ORTEGA, R. y DEL REY, R. (2003): La violencia escolar. Estrategias de prevención, Barcelona, Graó.

SMITH, P. K. (2003): Violence in Schools: The Response from Europe, Londres, Routledge.

SUBIRATS, M. y BRULLET, C. (1988): Rosa y Azul. La transmisión de los géneros en la escuela mixta, Madrid, Instituto de la Mujer.

SUBIRATS, M. y TOMÉ, A. (1992): Pautas de observación para el análisis del sexismo en el ámbito educativo, Cuadernos para la Coeducación, $\mathrm{n}^{\circ}$ 2, Institut de Ciències de l’Educaciò, Barcelona, Universidad Autónoma de Barcelona. 


\section{Breve currículo:}

\section{Fernando González Pozuelo}

Estudió en las Universidades de Roma y Salamanca, donde se doctoró en 1986. Profesor de Sociología en la Universidad de Extremadura desde 1976. En la actualidad es Catedrático de Sociología de Escuela Universitaria en la Facultad de Educación de la Universidad de Extremadura. Ha publicado varios libros de contenido sociológico sobre la sociedad extremeña: Estudio sociológico de la mujer en Badajoz (1988), Nuestros mayores: estudio sociológico de la tercera edad en Badajoz (1995), La salud en la ciudad de Badajoz: estudio sociológico de la situación sanitaria pacense (1995), Jóvenes extremeños 1995: estudio sociológico de la juventud de Badajoz y Cáceres (1996), Juventud universitaria extremeña del 2000 (1999), Escolares extremeños del 2000 (2001) y Estudio sociológico del profesorado extremeño de primaria y secundaria (2005). 